\title{
Use of an east end children's accident and emergency department for infants: a failure of primary health care?
}

\author{
H E Bedford, S M Jenkins, C Shore, P A Kenny
}

Department of Paediatric Epidemiology, Institute of Child Health, London WC1N 1EH $H$ E Bedford, research health visito

Department of Community Child Health, City and Hackney Health Authority

S M Jenkins, consultant community paediatrician

Queen Elizabeth Hospital for Children, Hackney

C Shore, clinical nurse specialist

P A Kenny, consultant paediatrician

Correspondance to: $\mathrm{Ms}$ Bedford

Accepted for publication 13 January 1992

\section{Abstract}

Objective - To ascertain why parents use an accident and emergency department for health care for their infants.

Design - Prospective one month study.

Setting - One accident and emergency department of a children's hospital in the east end of London.

Subjects - Parents of 159 infants aged $<9$ months attending as self referrals (excluding infants attending previously or inpatients within one month, parents advised by the hospital to attend if concerned about their child's health, infants born abroad and arrived in Britain within the previous month).

Main measures - Details of birth, postnatal hospital stay, contact with health professionals, perceptions of roles of community midwife and health visitor, and current attendance obtained from a semistructured questionnaire administered in the department by a research health visitor; diagnosis, discharge, and follow up.

Results - 152(96\%) parents were interviewed, $43(28 \%)$ of whom were single parent and $68(45 \%)$ first time mothers. Presenting symptoms included diarrhoea or vomiting, or both $(34,22 \%)$, crying (21, $14 \%)$, and feeding difficulties $(10,7 \%)$. Respiratory or gastrointestinal infection was diagnosed in $70(46 \%)$ infants. Only $17(11 \%)$ infants were admitted; hospital follow up was arranged for $27(20 \%)$ infants not admitted. Most (141, 94\%) parents were registered with a general practitioner; $146(27 \%)$ had contact with the community midwife and $135(89 \%)$ the health visitor.

Conclusion - Most attendances were for problems more appropriately dealt with by primary care professionals owing to patients' perceptions of hospital and primary health care services.

Implications - Closer cooperation within the health service is needed to provide a service responsive to the real needs of patients.

\section{Introduction}

It is well recognised that general accident and emergency departments in inner London and other urban areas are used for primary health care services in addition to their designated function. ${ }^{1}$ This is also true for these departments in children's hospitals ${ }^{2}$; social and medical circumstances will determine whether or not parents bring their children to hospital. ${ }^{3}$

Routine monitoring of attendances in the accident and emergency department of a children's hospital in the east end of London, together with a survey of its use by patients during one month in 1989 , confirmed that a large proportion of self referred infants were aged under 6 months, were from the locality of the hospital, and presented with problems which might be considered inappropriate - for example, difficulties with feeding. ${ }^{4}$

We conducted a study to investigate in more detail the reasons why parents of young babies use this facility, in the context of their social circumstances and experiences with primary care services. The aim was to identify where service provision within the hospital and community could be improved.

\section{Subjects and methods}

All parents attending the department as self referrals with children aged under 9 months during September 1989 were eligible for inclusion in the study. Parents were excluded if they had been referred by their general practitioner or other agency; they had attended the department or their child had been an inpatient within the previous month; they had been previously advised by the hospital to bring their child to the department if they were ever concerned; their babies had been born abroad and the parents had immigrated within the previous month. Parents who attended with their child more than once were interviewed on only the first occasion.

Parents who had registered their child at the accident and emergency reception and were waiting to be seen by a doctor were approached by the interviewer, who explained the purpose of the study and assured anonymity and confidentiality and obtained their consent to be interviewed. Parents who attended when the interviewer was not available were given a letter by staff of the department informing them of the study and advising them that the interviewer would be making contact shortly. These parents were subsequently interviewed within five days of their attendance either by telephone or, if they were not available by phone, at home, having first been contacted by letter.

All interviews were conducted by $\mathrm{HB}$, who for the period of data collection was available 
in the department from 9 am to 10 pm daily, including weekends. Information was collected from a semistructured interview consisting of open ended questions; it included details of the child's birth and postnatal hospital stay, contact with health professionals, and parents' perceptions of the roles of community midwife and health visitor. The mothers were asked if the health visitor had offered them advice on three specific issues: immunisation, infant feeding, and child care - for example, clothing and hygiene. Parents were asked who they would ask for advice in two hypothetical situations: when their infant had a fever or had diarrhoea and vomiting. In addition, they were asked for details of the attendance including the nature and duration of the child's problem; the reason for attending at the department rather than at primary care services; and whether they had previously sought medical or other advice. Details of diagnosis, discharge, and follow up were transcribed from the medical records.

\section{Results}

A total of 228 infants aged under 9 months attended during the study period, $17(7 \%)$ of whom attended more than once. Sixty nine children were excluded: $49(21 \%)$ had been referred by their general practitioner and $4(2 \%)$ by another agency. Of the remaining 16 infants excluded, two had chronic conditions and their parents had been advised to attend the department if they were ever concerned; two had been inpatients within the past month; two had been born abroad and arrived in Britain within the previous two weeks; and 10 had previously attended in the previous month, and their parents had been advised to return if they were concerned.

Thus 159 children were eligible for inclusion in the study. One hundred and fifty two parents (response rate $96 \%$ ) were interviewed, and none refused to participate; the $7(4 \%)$ parents who were not interviewed included those of families who could not be traced at the address recorded or who failed to keep the appointment for interview. In all, 116(76\%) were interviewed at the time of their attendance or in the ward after admission; the remainder were contacted either by telephone or visited at home.

\section{DETAILS OF FAMILIES}

Most $(101,66 \%)$ parents lived in the two adjacent health districts in the immediate locality of the hospital, although $17(11 \%)$ had travelled as far as $30 \mathrm{~km}$ or so $(20$ miles) to attend this particular department. Eighty $(53 \%)$ parents were white and had been born in the United Kingdom, 29(19\%) were of Asian origin with 22 having been born in the Indian subcontinent, $13(9 \%)$ were of African or West Indian origin, and five families were Kurdish. The interviewer experienced language difficulties with 23 families, although in most cases the father spoke sufficient English to enable the information to be elicited. An interpreter was used on two occasions but was not available outside normal working hours; six families had brought an English speaking relative or friend with them. Forty three $(28 \%)$ parents were single parent mothers and $68(45 \%)$ first time mothers. The mean age of the babies was 4 months (range 6 days -9 months, median 3 months 3 weeks); five children were aged under 10 days.

POSTNATAL HOSPITAL STAY

The infants had been born in 16 different hospitals with three having been born abroad.

Eighty four (55\%) were born in the two main maternity units in the local health districts. Mothers had stayed in hospital for an average of three days after delivery (range $<1$ day-12 days, median 3 days). Of 149 mothers delivered in the United Kingdom, 61(41\%) recalled having been advised about infant feeding while in hospital; mothers who stayed in hospital for five days or longer were more likely to recall receiving advice, $7(11 \%)$ mothers had had to ask for advice, and $9(15 \%)$ commented that once they had decided to bottle feed their baby hospital staff failed to give them any information or practical help such as making up feeds. The extent of support in these cases was limited to "breast is best." Seventy one (48\%) mothers could not recall having been given any advice whatsoever about feeding during their hospital stay. The remaining 17 women $(11 \%)$ did not think they needed such advice as they had older children.

CONTACT WITH COMMUNITY HEALTH SERVICES

Most parents were in contact with primary health care services: 146(96\%) had been visited by the community midwife and $135(89 \%)$ by the health visitor, and they knew how to contact these services if necessary. Most $(141,94 \%)$ were registered with a general practitioner, and 131 of these $(93 \%)$ had not found difficulty in obtaining an appointment for consultation. One hundred and sixteen parents $(76 \%)$ had attended a child health clinic run by either the district health authority or general practitioner. Of the 36 who had not, $27(75 \%)$ had infants aged under 6 weeks and were planning to attend for the 6 week developmental assessment.

In all, 115(76\%) mothers recalled receiving advice from the health visitor about immunisation, $70(46 \%)$ about babycare, and $86(57 \%)$ about infant feeding. Fifteen $(10 \%)$ recalled being offered advice about general child care as opposed to specific medical care by their general practitioner or the clinical medical officer.

PERCEPTIONS OF ROLE OF COMMUNITY STAFF

Midwives - In total, $108(71 \%)$ mothers described midwives as being concerned with the "health and welfare of mother and baby," $15(10 \%)$ did not know their role, and a further $17(11 \%)$ thought that they visited merely to fulfil a statutory requirement. The remainder $(12,8 \%)$ thought that the midwife became involved only if there was a specific problem 
with either mother or baby. Mothers generally expressed a positive attitude to the midwife.

Health visitors - Of 135 mothers who had been visited by a health visitor, $76(56 \%)$ said that they were concerned with the health and welfare of the children or mother, or both; $4(3 \%)$ explicitly mentioned the health visitor as a source of health advice; $6(4 \%)$ said that the health visitor was being nosey and only asked questions; and $12(9 \%)$ that the health visitor's function was in checking that the housing was suitable, safe, and clean; one mother commented "... why do you think they always ask to use the toilet, so they can check it's clean." Eleven ( $8 \%$ ) mothers thought that their health visitor visited only to tell them to go to the clinic or called because they had not attended. The remainder claimed not to know the health visitor's role or could not see a need for them. One hundred and two $(76 \%)$ mothers reported useful contact with the health visitor; the remainder had either a negative or ambivalent attitude.

\section{CHILDREN'S HEALTH}

Of the 152 infants, $121(80 \%)$ were reported to have been entirely well since birth; $22(14 \%)$ had had minor illnesses such as coughs and colds. Eleven children (7\%) had had a previous hospital admission, two of whom had been seriously ill, with pneumonia and pertussis.

Seventy eight $(51 \%)$ women said that they would consult their general practitioner, and $30(20 \%)$ would telephone or attend the hospital if their child had diarrhoea and vomiting; $6(4 \%)$ would ask their health visitor for advice and $38(25 \%)$ would ask a friend or relative or treat the child at home. Sixty five $(43 \%)$ parents would ask their general practitioner and $20(13 \%)$ would ask the hospital for advice about a fever; $28(18 \%)$ said they would consult a relative or friend and $5(3 \%)$ that they would consult the health visitor; the remainder would ask no one or treat the child at home.

REASONS FOR ATTENDANCE AT DEPARTMENT Table 1 shows parents' reasons for attending the department. For $37(24 \%)$ parents the reason was a positive perception of the hospital: 25 parents considered the department to have a good reputation and to be well equipped for children, nine said that they wanted to see a children's doctor, and three thought they would obtain immediate

Table 1 Parents' reasons for attending accident and emergency department with child

\begin{tabular}{lrr}
\hline & No & $(\%)$ \\
\hline Positive perception of department & 37 & $(24)$ \\
Condition of child worse or no better & 35 & $(23)$ \\
Difficulty in access to general practitioner & 28 & $(18)$ \\
Poor perception of general practitioner & 16 & $(11)$ \\
Advised to do so & 15 & $(10)$ \\
Most appropriate place & 11 & $(7)$ \\
Convenience & 3 & $(2)$ \\
Wanted second opinion & 2 & $(1)$ \\
Family history of child death & 2 & $(1)$ \\
Other & 3 & $(2)$ \\
\hline Total & 152 & $(100)$ \\
\hline
\end{tabular}

Table 2 Presenting symptoms described by parents for 152 infants

\begin{tabular}{lcr}
\hline & No & $(\%)$ \\
\hline Diarrhoea or vomiting, or both & 34 & $(22)$ \\
Crying & 21 & $(14)$ \\
Cough or cold or sore ears & 22 & $(14)$ \\
Not feeding & 10 & $(7)$ \\
Difficulty in breathing & 12 & $(8)$ \\
Fever & 11 & $(7)$ \\
Rash & 13 & $(9)$ \\
Accident & 13 & $(9)$ \\
Other & 16 & $(11)$ \\
\hline
\end{tabular}

attention. Of 141 parents registered with a general practitioner, $28(20 \%)$ said that they had experienced difficulty in seeing their own doctor; $16(11 \%)$ mentioned a lack of confidence in their doctor because of advice given on this or a previous occasion. One hundred and seven parents $(70 \%)$ had sought advice about the presenting complaint before they came to the department: $48(45 \%)$ from their general practitioner; $20(19 \%)$ from friends and relatives; and the remainder from the clinic doctor $(3,3 \%)$, health visitor (4, $4 \%$ ), or a combination of friends, relatives, and health professionals $(32,30 \%)$. Ninety five $(63 \%)$ parents attended the department between $4 \mathrm{pm}$ and midnight, 37(24\%) attended on a Sunday, and $15(10 \%)$ on a Saturday.

PRESENTING SYMPTOMS AND DIAGNOSES

Tables 2 and 3 show the presenting symptoms of the infants and the diagnoses. Fifty six $(37 \%)$ infants had had their symptoms for less than 24 hours and $42(28 \%)$ for longer than a week; $9(6 \%)$ mothers reported symptoms in their infants since birth, including symptoms in two infants with neonatal jaundice. Mothers of babies who had had symptoms for longer were more likely to have sought advice before attending and to be seeking a second opinion. Diarrhoea or vomiting, or both, were the most frequently mentioned symptoms (34, $22 \%$ ), but $21(14 \%)$ parents had attended because of their infant's persistent crying and $10(7 \%)$ because of difficulties with feeding. Thirteen infants (9\%) attended after an accident; for two infants this was the second such attendance. A respiratory or gastrointestinal infection was diagnosed by doctors in $70(46 \%)$ infants. Seventeen $(11 \%)$ infants were considered to be well, but their parents were anxious about their symptoms; of these, eight infants were aged under 3 months and one under 10 days. A further 10 babies were confirmed as being well but having feeding problems.

Table 3 Diagnosis of accident and emergency doctors for 152 infants

\begin{tabular}{lrr}
\hline & No & $(\%)$ \\
\hline Respiratory infection & 38 & $(25)$ \\
Gastrointestinal infection & 32 & $(21)$ \\
Well or no problem & 17 & $(11)$ \\
Injury or accident & 15 & $(10)$ \\
Rash & 12 & $(8)$ \\
Feeding problem & 10 & $(7)$ \\
Cough or cold or otitis media & 9 & $(6)$ \\
Other & 19 & $(12)$ \\
\hline
\end{tabular}


Table 4 Outcome of visit for 152 infants

\begin{tabular}{lrr}
\hline & No & $(\%)$ \\
\hline Sent home & 49 & $(32)$ \\
Sent home, to return if concerned & 46 & $(30)$ \\
Sent home, follow up in department & 18 & $(12)$ \\
Admitted & 17 & $(11)$ \\
Sent home, referred to health visitor or & 8 & $(5)$ \\
$\quad$ general practitioner & 6 & $(4)$ \\
Sent home, follow up in outpatient & & \\
department & 3 & $(2)$ \\
Sent home, follow up by nurse specialist & 3 & $(2)$ \\
Sent home, follow up by other hospital & 2 & $(1)$ \\
Refused admission & &
\end{tabular}

OUTCOME

Table 4 shows the outcome of attendance. Seventeen infants $(11 \%)$ were admitted: seven with gastrointestinal infections and seven with respiratory infections; two infants were admitted for observation after an accident and one for investigation of unexplained fever. The largest proportion $(49,32 \%)$ were discharged with advice or medication.

Of the 135 infants who were not admitted, $46(34 \%)$ were sent home with advice to their parents to return if they remained concerned about their infants or their infants were no better; these infants had varying diagnoses, and six were considered to be well. Follow up by the hospital in either the accident and emergency or outpatient department was arranged for $27(20 \%)$ infants; eight $(6 \%)$ were referred to their general practitioner or health visitor and included one child who had had an accident, two whose parents were considered to be anxious, and one with a feeding problem.

\section{Discussion}

The possibility of recall bias is important in this type of investigation. Parents of infants aged under 9 months were chosen for the study sample as they would still recall events occurring in the early postnatal period. This is also the period when families have greatest contact with primary health care workers such as midwives, health visitors, and doctors as a result of child health service provision. There is considerable evidence to show that mothers have good recall of events occurring in the antenatal and postnatal periods; for some experiences mothers are more reliable sources of information than hospital records. ${ }^{5}$

This hospital serves one of the most disadvantaged inner city areas in the United Kingdom. ${ }^{6}$ The parents in this study were representative of the population of the surrounding health districts: a socially and economically deprived group, with a high rate of unemployment and diverse ethnic background. The difficulties in providing health care services in such an area are well recognised. ${ }^{7}$ In the two surrounding health districts the provision of health services is compounded further by an overstretched health visiting service with large caseloads, frozen and vacant posts, and high rates of staff sickness (I Waters, personal communication). The findings from this study suggest that this is having an impact on service users.

APPROPRIATENESS OF ATTENDANCE

Only $11 \%$ of infants presenting at the accident and emergency department required admission, most had problems which we consider could have been appropriately dealt with by primary health care services. For example, $18 \%$ of infants were thought to be well or to have feeding problems, and it seemed that parental anxiety or lack of confidence in parenting skills, or both, prompted attendance. Most parents expressed no difficulty in contacting their general practitioner or health visitor, but many of the attendances were outside normal working hours for non-urgent conditions in children who had had symptoms for some time; almost half the parents were seeking a second professional opinion.

NEEDS OF PARENTS

Nearly half the parents in this study were first time mothers, who are likely to be less confident in assessing symptoms and dealing with illness than more experienced mothers. Almost a third were single and living alone with their children. Such social isolation, without an immediate source of advice and support from family or partner, is a contributory factor in development of depression. ${ }^{8}$ Parents have a need for easy access to a ready source of advice when confronted with sudden anxieties about their children. Mothers, particularly, are often required (with no formal training and minimal experience) to make complex decisions about managing unwell children; most episodes of illness are dealt with at home without recourse to consulting health professionals."

CONTINUITY OF CARE

It is particularly important that health visitors and general practitioners are aware that parents are using the accident and emergency department as a source of advice for nonurgent problems so that they may target services appropriately. Notification of attendances by all infants aged under 1 year is made routinely to the relevant health visitor, but this is generally undertaken by the nursing staff of the department and comprises only basic details of the attendance. Community health staff require more detailed information to plan future support and management. Such referrals, in which accident and emergency staff contacted the health visitor or general practitioner directly by letter or telephone, occurred for only a few infants.

ACCESS TO PRIMARY CARE SERVICES

Twenty two per cent of parents had no use of a telephone. Mothers most likely to use an accident and emergency department for their unwell child are those registered with practices who use deputising services, those with no telephone, and those from lower social class groups, factors which are all interrelated. ${ }^{10}$ Many parents remain confused about the differing roles of health professionals. Understanding the complexity of services is particularly difficult for parents from ethnic groups whose first language is not English. ${ }^{11} 12$ 
Almost a quarter of mothers expressed negative or ambivalent attitudes to health visitors, a rate consistent with other studies. ${ }^{13}$ A similar proportion did not recall having received advice about immunisation and nearly a half about feeding. Parental recall of advice, however, is not always accurate, ${ }^{14}$ which may be true particularly for parents with additional social and economic problems. This is reflected in the mothers' perceptions of the health visitor's role: few mothers considered health visitors to be a provider of health advice or consulted them about their child's condition before attending the department. Health visitors are well placed to identify particularly vulnerable parents, who may need more support to develop their parenting skills, and to provide them with structured information on the roles of health professionals and the use of services generally. This could include guidance on recognising and managing minor illness, although this has not generally been perceived as part of the health visitor's role. Such information can usefully be reinforced by general practitioners and clinical medical officers during consultations for particular problems.

\section{LIAISON BETWEEN HOSPITAL AND COMMUNITY} CARE

In order to improve two way communication between staff of the accident and emergency department and primary health care workers and to make primary care more accessible to parents it is intended to appoint a liaison health visitor to the department. This health visitor will be an additional source of advice to the department on managing common presenting disorders and will provide immediate access to the appropriate primary health care worker, undertake referrals to the community, and develop an overview of attendances to allow - for example, identification of infants having repeated accidents or early recognition of suspected child abuse. ${ }^{15} \mathrm{He}$ or she will also be able to give parents attending the department advice and support as required. Referral to other community based agencies and support schemes, such as Homestart, when appropriate, will also be facilitated. ${ }^{16}$ This appointment will be evaluated in due course.

Other approaches to ensure improved communication could include the rotation of junior medical staff between hospital and community posts, which is increasing nationally. Regular meetings between accident and emergency and community staff have been found useful (S Jenkins, P Kenny, personal communication).

It is of particular concern that even in this young age group $9 \%$ of babies presented as a result of accidents, two because of a second accident. All health professionals have a reponsibility to discuss accident prevention with parents. $^{17}$ Increasingly, accident prevention is being incorporated into child health surveillance programmes, and hospitals have an additional and important role in establishing further health promotion initiatives. Health professionals in all settings need to respond to parents' needs and direct them to the most appropriate services to ensure that they receive the best quality care for their infants. In this study a group of parents who had access to health visitors and general practitioners used the accident and emergency department as a back up or alternative service for non-urgent problems. Inevitably, a specialist children's hospital is viewed by concerned parents as the appropriate place to take a sick child. However, it is important to modify this pattern of use so that those attending as genuine accidents or emergencies or with less urgent health needs each receive the most appropriate care. Primary health care teams are better placed than an accident and emergency department to provide the support and continuity of care that parents of infants in this latter group may require.

1 London Health Care Planning Consortium Study Group. Primary health care in inner London. London; LHCPC 1981

2 Bowling A, Issacs D, Armston J, Roberts JE, Elliott EJ. Patient use of a paediatric hospital casualty department in the east end of London. Fam Pract 1987;4:85-90.

3 Wilkinson A, Kazantzis G, Williams DJ, Dewar RAD, Bristow KM, Miller DL. Attendance at a London Bristow KM, Miller DL. Attendance at a London casualty

4 Farquhar $M$. The use and mis-use of paediatric casualty. Nursing Standard 1990;4:34-5.

5 Martin C. Monitoring maternity services by postal questionnaire: congruity between mothers' reports and their obstetric records. Stat Med 1987;6:613-27.

6 Department of Public Health, City and Hackney Health Authority. Health in Hackney 1989. London: City and Hackney Health Authority, 1990. (Annual public health report.)

7 Jarman B. Identification of underprivileged areas. BMF 1983;286:1705-9.

8 Brown GW, Harris T. Social origins of depression. London: Tavistock Publications, 1978.

9 Spencer NI. Parents' recognition of the ill child. In: MacFarlane A, ed. Progress in child health. Vol 1. MacFarlane A, ed. Progress in child health.

10 Mayall B. Keeping children healthy. London: Allen and Unwin, 1986.

11 Atun R, Jenkins S. Health needs of the Turkish community. In: Health in Hackney 1990. London: City and Hackney Health Authority, 1991:95-6. (Annual public health report.)

12 Watson E. Health of infants and use of health services by mothers of different ethnic groups in East London. Community Medicine 1984;6:127-35.

13 Clark J. Mothers' perceptions of health visiting. Health Visitor 1984;57:265-8.

14 Watson E. A mismatch of goals? Health Visitor 1986;59: 75-7.

15 Dean CA. Health visitor/paediatric liaison officer. Health Visitor 1985;58:221.

16 Harrison M, Hart L. Home-start. In: MacFarlane A, ed Progress in child health. Vol 3. Edinburgh: Churchill Livingstone, 1987:190-8.

17 Child Accident Prevention Trust. Who's who in child accident prevention. London: CAPT, 1991. 